\title{
Collaborative R\&D and Pricing Policy of Supply Chain under the Selection Behavior of Heterogeneous Customer
}

\author{
Bo Huang $\mathbb{D},{ }^{1,2}$ Thomas L. Saaty, ${ }^{2}$ and Yuyu Li $\mathbb{D}^{3}$ \\ ${ }^{1}$ School of Economics and Business Administration, Chongqing University, Chongqing, China \\ ${ }^{2}$ Joseph M. Katz Graduate School of Business, University of Pittsburgh, Pittsburgh, PA, USA \\ ${ }^{3}$ College of Computer and Information Science, Chongqing Normal University, Chongqing, China
}

Correspondence should be addressed to Yuyu Li; lyyjame@163.com

Received 11 January 2019; Revised 10 April 2019; Accepted 21 April 2019; Published 6 May 2019

Academic Editor: Elio Masciari

Copyright (C) 2019 Bo Huang et al. This is an open access article distributed under the Creative Commons Attribution License, which permits unrestricted use, distribution, and reproduction in any medium, provided the original work is properly cited.

\begin{abstract}
Considering that a manufacturer and its core part supplier make collaborative R\&D on serial products of 3 grades, high-, mid-, and low-grade, and their core parts according to costumers' preference for the performance, or intrinsic value, of products, we propose a collaborative R\&D model based on costumers' selection behavior to study the collaborative R\&D policy and pricing policy of the supply chain. Then we establish a bargaining game model to study how they allocate the profit they earned. We obtain the optimal policies through theoretic and experimental analysis, and we use Apple iPhone case to illustrate the models and conclusions of this paper. It is found that if the aim of the supply chain is only to maximize its total profit, it should only develop the high-grade product and make its price half of its intrinsic value; if the aim of the supply chain is to maximizing profit while increasing the sales and market shares of the serial products, it should at least develop the high-grade and low-grade product; the ratio of price between the higher grade and the lower grade should be greater than the corresponding ratio of the intrinsic value, while the difference of price between higher grade and the lower grade should be less than the corresponding difference of the intrinsic value.
\end{abstract}

\section{Introduction}

With the increasing competition and the rapid change in customers' demand, manufacturers must continually develop series products of multiple grades, which have the same core function but different performance, configuration, and quality, in order to better meet the personalized demands of heterogeneous customers [1]. However, around $80 \%$ of product innovation ends in failure each year, even Coca-Cola has developed the new Coke which has been sold in the market for only three months [2]; Apple, which is renowned for innovation, also has developed a Macintosh Portable laptop, Newton handheld computers, QuickTake digital cameras, and other large number of products, which are failures as they did not meet the demands of customers, or their prices were too high [3]. Therefore, it is crucial for manufacturers to make the right decision on developing the right serial products with right function and performance. Meanwhile, as the product's core part plays a key role in the function and performance of the product, many manufacturers invite their core part suppliers to conduct collaborative R\&D to make sure that the core part well matches all products of the same series [4]. It has become the key issue of a modern manufacturer building the competitive advantage that makes the collaborative R\&D and pricing policy of the product according to customers' preference and selection behavior, in order to develop a series of products satisfying demands of heterogeneous customers.

Most of the researches on product selection and/or pricing policy based on customer selection behavior focus on that of retail dealers [5-8]. Recently, some scholars began to make research on manufacturers' operation policies based on customer selection behavior. Li and Huang studied how the supply chain of product family makes the product selection and components replenishment policy of the product family according to the heterogeneity of the customer [9]. Shao and Ji analyzed the pricing policy of the ATO supply chain of two products under customer heterogeneity preferences [10]. Schön studied how the supply chain makes price discrimination and product line selection policy based on customer choice behavior by establishing attraction choice 
models [11, 12]; Li, Dan, and Huang analyzed the impact of customer selection and out-of-stock substitution on supply chain product pricing and component replenishment decisions [13]. Ding et al. considered the customer's preference for luxury and environmental protection and studied the pricing policy for remanufacturers [14]. However, none of the above studies is related to how manufacturers develop their product R\&D and pricing policies based on customers' selection behavior.

As the main mode of collaborative $\mathrm{R} \& \mathrm{D}$, the collaborative $R \& D$ of supply chain has been of widespread concern and deeply studied. $\mathrm{Ge}, \mathrm{Hu}$, and Xia studied the supply chain cooperative $\mathrm{R} \& \mathrm{D}$ investment policy and product producing policy under the assumption that the upstream and downstream enterprises of the supply chain cooperate in R\&D and determine the yield of product according to the wholesale price of the product [15]. Frascatore found that the profits of both the upstream and downstream enterprise of the supply chain will be raised if the upstream enterprise invests in the downstream enterprise's $R \& D$ of reducing production costs [16]. Matsui studied the impact of pricing methods of total-cost-based and variable-cost-based on the supply chain cooperative $\mathrm{R} \& \mathrm{D}$ policy under the condition that risk aversion production executives face the uncertainty of R\&D investment [17]. Wang, Ji, and Ming found that the perfect shared contract of the information products supply chain can more effectively promote the transfer and absorption of knowledge among partners [18]. Chen, Zhang, and Song applied principal-agent theory to design the knowledge trading incentive mechanism for upstream and downstream enterprises of the supply chain based on the existence of bilateral moral hazard between supply chain enterprises [19]. $\mathrm{Xu}$, Zheng, and Chen constructed six collaborative R\&D and pricing models of two-level supply chain and proposed the methods of obtaining the optimal solution of the models [20]. However, none of the above literature considered whether the products meet the demands of customers. However, as we mentioned above, heterogeneous customers have different preferences on product's performance, configuration, and price, and ignoring that may cause manufacturers to develop products that do not meet customers' demands. Therefore, the manufacturer should take into account customers' selection behavior when making supply chain collaborative R\&D and product pricing policy with its core part supplier.

In this paper, we assume that the supply chain consists of one manufacturer and one core part supplier, and the manufacturer invites its supplier to make collaborative R\&D on 3-grade products, including high-, mid-, and low-grade products, and their core part. Customers make their purchase decision according to their heterogeneous preferences on products' performance and configuration or their selection behavior. We propose a supply chain collaborative $R \& D$ model based on customer selection behavior, in order to study how the manufacturer and its core part supplier make their collaborative R\&D policy and product pricing policy to better meet individualized demands of heterogeneous customers. Then we establish a bargaining game model to study how they allocate the profit they earned. Through theoretic and experimental analysis, we obtain the optimal policies of the supply chain, including the products that should be developed, their corresponding R\&D investment, and their allocation proportion of profit. Finally, we use Apple iPhone case to illustrate the models and conclusions of this paper.

\section{Problem Description and the Collaborative R\&D Model}

2.1. Problem Description. A manufacturer plans to develop a series of products of 3 grades, high, medium, and low. These 3 grades of products have the same core function, but different performance, quality, appearance, and configuration, which can be regarded as the intrinsic value of product. This is very common in reality. For example, in China, the vast majority of automobile manufacturers provide high-, mid-, and lowgrade cars to customers, and the JS110-B series of Jianshe Motorcycle consists of products of BF3 (high-grade), Ling Ya (mid-grade), and Ling Ying (low-grade).

In the market, there are heterogeneous potential customers, who have their individual preference on the series of products. In other words, the same product brings different utilities to different customers. When customers face the products provided by the manufacturer, they make their purchase decision by comparing the net utilities, or utilities of products minus their prices, brought by the products. The criterion of customers making purchase decision is buying the product which brings the highest nonnegative utility to them. When customers buy products, their potential demands on the series of products change into actual demands.

As the core part of the products plays a key role in the function and performance of the products, the manufacturer invited its core part supplier to make collaborative R\&D with it. In the traditional cooperation of supply chain, suppliers and manufacturers make decentralized decisions; that is, they make their own cooperation strategy with the goal of maximizing their own profits. This will lead to the loss of the total profit of the supply chain and their own profits due to the double marginalization. As market competition has changed from traditional competition between enterprises to competition between supply chains, in order to provide the overall competitiveness of the supply chain, suppliers and manufacturers are transformed from traditional decentralized decision-making to centralized decision-making. In other words, they make the related policies with the goal of maximizing the total profit of the supply chain, and then they allocate the total profit through bargaining or other means [21]. Therefore, in this paper, the manufacturer and its core part supplier apply centralized decision-making to make the investment policies of both parties with the goal of maximizing the total profit of collaborative R\&D. Specifically, according to customers' preference, or their selection behavior, on the 3 grades of product, they make joint decision on which grade(s) of product they should make R\&D investment in; in other words, they will select the right grade(s) of product to develop. Besides, they make joint decision on how much they should invest, respectively, and the prices of the grade(s) of product. In classical economics, a firm's goal is maximizing its profit. However, when facing the 
very fierce market competition, the firm has to take account of the sales volume or market share of its product. Therefore, in this paper, we study how the manufacturer and its core part supplier make their R\&D investment policies to maximize the total profit with the constraint of sales volume.

After they finish the collaborative $R \& D$, the manufacturers release the grade(s) of product and obtain profit. Then, they allocate the profit of collaborative R\&D through bargaining.

In this paper, we propose a collaborative $R \& D$ and pricing model to study how the manufacturer and its core part supplier jointly select the right grade(s) of product to develop and make their decision on the amount of their respective $\mathrm{R} \& \mathrm{D}$ investment, and how the manufacturer prices the grade(s) of product according to the selection behavior of heterogeneous customers. And we develop a bargaining game model to study how the manufacturer and its core part supplier allocate the profit of collaborative R\&D.

\subsection{The Collaborative R\&D Model. A manufacturer (labeled} as e) plans to develop a series of products for a market with heterogeneous customers. The series of products includes 3 grades of products, high-, mid-, and low-grade products (labeled as $h, m$, and $l$, respectively). The 3 grades of products have the same core function, but different performance, quality, appearance, and configuration, which can be regarded as the intrinsic value of product (hereinafter shortened as "value"). Obviously, the value of the high-grade product (labeled as $V_{h}$ ) is the highest, and the value of the mid-grade product (labeled as $V_{m}$ ) is higher than that of the low-grade product (labeled as $V_{l}$ ).

In the market, there are heterogeneous customers with a total potential demand, $D$, for the series of products, or all the 3 grades of products. The heterogeneous customers have their own individual preference and evaluation on the high-, mid-, and low- grade product. Some customers prefer highgrade product; some customers pay more attention to the price-performance; some customers are more willing to buy low-grade product with low price. As a matter of course, all customers agree that the value of high-grade product is the best, the value of mid-grade product is the second, and the value of low-grade product is the lowest. In other words, the utilities of the same product brought to different customers are different, and the utility of the high-, mid-, and low-grade product brought to customers is $\rho V_{i}, i=h, m, l$, where $\rho$ is the customers' heterogeneous preference on the value of product of grade $i$, and $\rho$ follows uniform distribution of $[0,1]$, that is, $\rho \sim \mathrm{U}(0,1)[9,10]$.

The potential demand of each potential customer is one; that is, each potential customer buys only one product from the whole series of products at most. When facing the series of products provided by the manufacturer, the potential customers make their purchase decision, determining whether or not to purchase and which grade of product to purchase. The criterion of customers' purchase decision-making is to buy the grade of product bringing the highest net utility, or the utility brought by product minus its price, $\rho V_{i}-P_{i}$, $i=h, m, l$, where $P_{i}$ is the price of product of grade $i$ and satisfies $P_{h}>P_{m}>P_{l}$. Specifically, if and only if a potential customer's net utility from product of grade $i, i=h, m, l$, is nonnegative and the highest in the whole series of products, the potential customer will purchase the product of that grade, and the potential demand of this customer becomes an actual demand. As a matter of course, when the performance and configuration of the 3 grades of products and their prices are determined, the net utilities they bring to customers are determined, and their actual demands are determined too. We label the ratio of actual demand of product of grade $i$ to total potential demand as $\delta_{i}$ (hereinafter referred to as "demand realization rate"); that is, the actual demand of product of grade $i$ is $\delta_{i} D$.

As the performance parameter of its core part is crucial to the performance of the series of product, the manufacturer invites its core part supplier (labeled as $s$ ) to conduct collaborative $\mathrm{R} \& \mathrm{D}$ to make the core part better meet the design and requirements of the series of product. In order to achieve the expected performance and configuration, or intrinsic value, the manufacturer and the supplier need to make the corresponding $\mathrm{R} \& \mathrm{D}$ investment, and the relationship between the value and $\mathrm{R} \& \mathrm{D}$ investment satisfies the CobbDouglas function $V=\gamma I_{e}^{\alpha} I_{s}^{\beta}$, where $\gamma>0$ is a fixed constant, representing the technical level of the collaborative $R \& D$ between the two enterprises (referred to as "technical level"); $0<\alpha, \beta<1$ are fixed constants and meet $\alpha+\beta<1$. $\alpha$ and $\beta$ are the output elastic coefficients of the $\mathrm{R} \& \mathrm{D}$ investment of the manufacturer and the supplier, respectively. $\alpha+\beta<$ 1 represents the decreasing returns to scale, or decreasing marginal utility of $\mathrm{R} \& \mathrm{D}$ investment. In other words, with the increase of $R \& D$ investment or the technical level, the increment of technical level from the same R\&D investment decreases, or we should make more R\&D investment to obtain the same increment of technical level [22].

The process of the collaborative R\&D is as follows. Firstly, aiming at the goal of maximizing the total profit of collaborative $\mathrm{R} \& \mathrm{D}$, taking into account the customers' selection behavior, the two enterprises determine the intrinsic value of product of each grade, $V_{i}, i=h, m, l$, and the corresponding amount of R\&D investment, $I_{e}$ and $I_{s}$. For example, a Boeing 777-200ER can be equipped with different engines, GE90115B, GE90-94B, or GE90-85B engine, where GE represents the General Electric Company. Those engines are different in thrust, which is determined GE. Therefore, the $V_{i}$ of a $777-200 E R$ is determined by both Boeing and GE. Then, the two enterprises make the collaborative R\&D investment and begin the collaborative $\mathrm{R} \& \mathrm{D}$ activities. The process of collaborative R\&D activities is as follows. Firstly, they develop high-grade product and then, based on the highgrade product, develop mid-grade and low-grade products through adjusting the design and performance of high-grade product (for example, Samsung developed S4 mini based on S4). Obviously, the adjustment of design still needs R\&D investment, but because it is only adjusting the design and performance of high-grade product, the relationship between R\&D investment and intrinsic value adjustment satisfies $|\Delta V|=\lambda I_{e}^{\alpha} I_{s}^{\beta}$, where $\lambda>\gamma>0$ is a fixed constant, reflecting collaborative $\mathrm{R} \& \mathrm{D}$ technical level of adjusting the design and performance of high-grade product. In order to facilitate reading and understanding, the following sections of this 
paper use $I_{e h}$ and $I_{s h}, I_{e m}$ and $I_{s m}, I_{e l}$ and $I_{s l}$, respectively, to represent the investment of manufacturer and the core part supplier in developing high-grade product, as well as the midgrade and low-grade products through value adjustment. The relationship between the value of product of grade $i$ and corresponding amount of collaborative $\mathrm{R} \& \mathrm{D}$ investment satisfies $V_{h}=\gamma I_{e h}^{\alpha} I_{s h}^{\beta},\left|V_{h}-V_{m}\right|=\lambda I_{e m}^{\alpha} I_{s m}^{\beta}$, and $\left|V_{h}-V_{l}\right|=\lambda I_{e l}^{\alpha} I_{s l}^{\beta} . \mid V_{h}-$ $V_{m} \mid=\lambda I_{e m}^{\alpha} I_{s m}^{\beta}$ indicates that when the manufacturer and the supplier finish the R\&D for high-grade product, they develop mid-grade product through adjusting the performance and function of high-grade product, such as Samsung developing S4 mini from S4. Therefore, the difference increases with the rise of R\&D investment. $\left|V_{h}-V_{l}\right|=\lambda I_{\text {el }}^{\alpha} I_{s l}^{\beta}$ is the same.

As a result, the total profit of the collaborative R\&D of the manufacturer and the supplier is as follows.

$$
\pi=\sum_{i=h, m, l}\left(P_{i} \delta_{i} D-I_{e i}-I_{s i}\right)
$$

\section{The Optimal Collaborative R\&D Policies}

In order to determine the intrinsic value of high-, mid-, and low-grade product, the manufacturer and the supplier should firstly find out the demand realization rate of the product of each grade given the values of the three grades of products.

Let $\rho_{i}=P_{i} / V_{i}, \rho_{i j}=\left(P_{i}-P_{j}\right) /\left(V_{i}-V_{j}\right), i, j=h, m, l$ and $i \neq j$; we can obtain Proposition 1 as follows.

Proposition 1. The manufacturer and the supplier make the intrinsic values and prices of the products of the high-, mid, and low-grade meet the following requirement: $P_{i}<V_{i}$, $P_{m} / P_{l}>V_{m} / V_{l}, P_{h} / P_{l}>V_{h} / V_{l}, P_{h}-P_{l}<V_{h}-V_{l}, P_{h}-P_{m}<$ $V_{h}-V_{m}$, and $\left(P_{h} V_{l}-P_{l} V_{h}\right)<\left(P_{m} V_{l}-P_{l} V_{m}\right)+\left(P_{h} V_{m}-P_{m} V_{h}\right)$. Then the demand realization rates of three grades of products are, respectively, $\delta_{l}=\left(P_{m} V_{l}-P_{l} V_{m}\right) / V_{l}\left(V_{m}-V_{l}\right), \delta_{m}=\left(P_{m} V_{l}-\right.$ $\left.P_{l} V_{m}-\left[\left(P_{m} V_{h}-P_{h} V_{m}\right)+\left(P_{h} V_{l}-P_{l} V_{h}\right)\right]\right) /\left(V_{h}-V_{m}\right)\left(V_{m}-V_{l}\right)$, and $\delta_{h}=\left(\left(V_{h}-V_{m}\right)-\left(P_{h}-P_{m}\right)\right) /\left(V_{h}-V_{m}\right)$.

Proof. From customers' criterion of purchase decisionmaking, we know that if a customer decides to buy a product of grade $i, i=h, m, l$, the customer's net utility of buying this grade of product is nonnegative and is the highest among those of buying the high-, mid-, and low-grade product.

If customers buy product of low-grade, or grade $l$, there must be $\rho V_{l}-P_{l} \geq 0, \rho V_{l}-P_{l}>\rho V_{m}-P_{m}$, and $\rho V_{l}-P_{l}>$ $\rho V_{h}-P_{h}$. Solving the above inequalities, we can obtain $\rho \geq$ $P_{l} / V_{l}, \rho<\left(P_{m}-P_{l}\right) /\left(V_{m}-V_{l}\right)$, and $\rho<\left(P_{h}-P_{l}\right) /\left(V_{h}-V_{l}\right)$; in other words, customers of $\rho \in\left[\rho_{l}, \min \left(\rho_{m l}, \rho_{h l}, 1\right)\right]$ buy product of grade $l$.

If customers buy product of mid-grade, or grade $m$, there must be $\rho V_{m}-P_{m} \geq 0, \rho V_{m}-P_{m}>\rho V_{l}-P_{l}$, and $\rho V_{m}-P_{m}>$ $\rho V_{h}-P_{h}$. Solving the above inequalities, we can obtain $\rho \geq$ $P_{m} / V_{m}, \rho>\left(P_{m}-P_{l}\right) /\left(V_{m}-V_{l}\right)$, and $\rho<\left(P_{h}-P_{m}\right) /\left(V_{h}-V_{m}\right)$; in other words, customers of $\rho \in\left[\max \left(\rho_{m}, \rho_{m l}\right), \min \left(\rho_{h m}, 1\right)\right]$ buy product of grade $m$.

If customers buy product of high-grade, or grade $h$, there must be $\rho V_{h}-P_{h} \geq 0, \rho V_{h}-P_{h}>\rho V_{l}-P_{l}$, and $\rho V_{h}-P_{h}>$ $\rho V_{m}-P_{m}$. Solving the above inequalities, we can obtain $\rho \geq$ $P_{h} / V_{h}, \rho>\left(P_{h}-P_{l}\right) /\left(V_{h}-V_{l}\right)$, and $\rho>\left(P_{h}-P_{m}\right) /\left(V_{h}-V_{m}\right)$; in other words, customers of $\rho \in\left[\max \left(\rho_{h}, \rho_{h l}, \rho_{h m}\right), 1\right]$ buy product of grade $h$.

Obviously, there are customers buying product of grade $i, i=h, m, l$, so the manufacturer will develop and produce this grade product. In other words, only when $\rho_{l}<$ $\min \left(\rho_{m l}, \rho_{h l}, 1\right)$, the manufacturer will develop product of grade $l$. Solving $\rho_{l}<1$, we can obtain $P_{l}<V_{l}$. Solving $\rho_{l}<\rho_{m l}$, we can obtain $\left(P_{m} V_{l}-P_{l} V_{m}\right) / V_{l}\left(V_{m}-V_{l}\right)>0$. Solving $\rho_{l}<\rho_{h l}$, we can obtain $\left(P_{h} V_{l}-P_{l} V_{h}\right) / V_{l}\left(V_{h}-V_{l}\right)>0$. Therefore, the manufacturer should make the values and prices of products satisfy $P_{l}<V_{l}, P_{m} V_{l}-P_{l} V_{m}>0$, and $P_{h} V_{l}-P_{l} V_{h}>0$.

Similarly, only when $\max \left(\rho_{m}, \rho_{m l}\right)<\min \left(\rho_{h m}, 1\right)$, there are customers buying product of grade $m$, and the manufacturer will also develop product of grade $m$. Solving $\rho_{m}<$ $\min \left(\rho_{h m}, 1\right)$, we can obtain $\left(P_{h} V_{m}-P_{m} V_{h}\right) / V_{m}\left(V_{h}-V_{m}\right)>0$ and $P_{m}<V_{m}$. Solving $\rho_{m l}<\min \left(\rho_{h m}, 1\right)$, we can obtain $P_{m}-P_{l}<V_{m}-V_{l}$ and $\left(\left(P_{m} V_{l}-P_{l} V_{m}\right)+\left(P_{h} V_{m}-P_{m} V_{h}\right)+\left(P_{l} V_{h}-\right.\right.$ $\left.\left.P_{h} V_{l}\right)\right) /\left(V_{h}-V_{m}\right)\left(V_{m}-V_{l}\right)>0$. Therefore, the manufacturer should make the values and prices of products satisfy $P_{m}<$ $V_{m}, P_{h} V_{m}-P_{m} V_{h}>0, P_{m}-P_{l}<V_{m}-V_{l}$, and $\left(P_{h} V_{l}-P_{l} V_{h}\right)<$ $\left(P_{m} V_{l}-P_{l} V_{m}\right)+\left(P_{h} V_{m}-P_{m} V_{h}\right)$.

Similarly, only if $\max \left(\rho_{h}, \rho_{h l}, \rho_{h m}\right)<1$, the manufacturer will develop product of grade $h$. Solving it, we can obtain $P_{h}<$ $V_{h}, P_{h}-P_{l}<V_{h}-V_{l}$, and $P_{h}-P_{m}<V_{h}-V_{m}$. Therefore, the manufacturer should make the values and prices of products satisfy $P_{h}<V_{h}, P_{h}-P_{l}<V_{h}-V_{l}$, and $P_{h}-P_{m}<V_{h}-V_{m}$.

Therefore, the manufacturer should make the values and prices of products satisfy $P_{i}<V_{i}, P_{m} / P_{l}>V_{m} / V_{l}, P_{h} / P_{l}>$ $V_{h} / V_{l}, P_{h}-P_{l}<V_{h}-V_{l}, P_{h}-P_{m}<V_{h}-V_{m}$, and $\left(P_{h} V_{l}-P_{l} V_{h}\right)<$ $\left(P_{m} V_{l}-P_{l} V_{m}\right)+\left(P_{h} V_{m}-P_{m} V_{h}\right)$.

When the above requirements are satisfied, $\rho_{l}<\rho_{m l}<$ $\rho_{h l}<1, \rho_{m}<\rho_{m l}, \max \left(\rho_{h}, \rho_{h l}\right)<\rho_{h m}<1$. Therefore, customers of $\rho \in\left[\rho_{l}, \rho_{m l}\right]$ will buy product of grade $l$; in other words, its demand realization rate is $\delta_{l}=\rho_{m l}-\rho_{l}=$ $\left(P_{m} V_{l}-P_{l} V_{m}\right) / V_{l}\left(V_{m}-V_{l}\right)$. Customers of $\rho \in\left[\rho_{m l}, \rho_{h m}\right]$ will buy product of grade $m$; in other words, its demand realization rate is $\delta_{m}=\rho_{h m}-\rho_{m l}=\left(P_{m} V_{l}-P_{l} V_{m}-\left[\left(P_{m} V_{h}-P_{h} V_{m}\right)+\left(P_{h} V_{l}-\right.\right.\right.$ $\left.\left.\left.P_{l} V_{h}\right)\right]\right) /\left(V_{h}-V_{m}\right)\left(V_{m}-V_{l}\right)$. Customers of $\rho \in\left[\rho_{h m}, 1\right]$ will buy product of grade $h$; in other words, its demand realization rate is $\delta_{h}=1-\rho_{h m}=\left(\left(V_{h}-V_{m}\right)-\left(P_{h}-P_{m}\right)\right) /\left(V_{h}-V_{m}\right)$.

As the prices of high-, mid-, and low-grade product are decision variable, and their values are determined by the manufacturer and the supplier through R\&D investment decision, all the constraints in Proposition 1 are compatible.

From Proposition 1, we can find that if the manufacturer wants all its products of all the 3 grades to have actual demand, the price of the product of each grade should be lower than its intrinsic value, and the difference between the prices of products of two grades should be reasonable, neither too big, nor too small. Specifically, the ratio of the price of mid-grade product to that of low-grade product should be bigger than the ratio of the value of mid-grade product to that of low-grade product; the ratio of the price of high-grade product to that of low-grade product should be bigger than the corresponding ratio of the value; the gap of price between the high-grade and mid-grade product should be less than the gap of value between the high-grade and mid-grade product; the gap of price between the high-grade product and 
low-grade product should be less than the corresponding gap of value.

3.1. The Optimal Collaborative ReD Policies Maximizing Total Profit. After determining the range of value and price of each grade, the manufacturer and the supplier apply centralized decision-making to jointly make the $\mathrm{R} \& \mathrm{D}$ investment policies of both parties, $I_{e i}$ and $I_{s i}, i=h, m, l$, in order to maximize their total profit of collaborative R\&D.

As at this stage, the manufacturer and the supplier just focus on the total profit of collaborative R\&D, disregarding profit allocation; they face the following programing.

$$
\begin{aligned}
\max _{P_{i}, I_{e i}, I_{s i}} & \sum_{i=h, m, l}\left(P_{i} \delta_{i} D-I_{e i}-I_{s i}\right), \\
\text { s.t. } & P_{i}, I_{e i}, I_{s i}, \delta_{i} \geq 0, \quad i=h, m, l
\end{aligned}
$$

Solving the above programing, we can obtain the optimal $\mathrm{R} \& \mathrm{D}$ investment of the manufacturer and the supplier, $I_{e i}^{*}$ and $I_{s i}^{*}$, and the optimal price of the products, $P_{i}^{*}, i=h, m, l$, as follows.

$$
\begin{aligned}
& I_{e h}^{*}=2^{-2 /(1-\alpha-\beta)} \alpha^{(1-\beta) /(1-\alpha-\beta)} \beta^{\beta /(1-\alpha-\beta)} \gamma^{1 /(1-\alpha-\beta)} D^{1 /(1-\alpha-\beta),}, \\
& I_{s h}^{*}=2^{-2 /(1-\alpha-\beta)} \alpha^{\alpha /(1-\alpha-\beta)} \beta^{(1-\alpha) /(1-\alpha-\beta)} \gamma^{1 /(1-\alpha-\beta)} D^{1 /(1-\alpha-\beta)}, \\
& I_{e m}^{*}=I_{s m}^{*}=I_{e l}^{*}=I_{s l}^{*}=0, \\
& P_{h}^{*} \\
& =2^{(-1-\alpha-\beta) /(1-\alpha-\beta)} \alpha^{\alpha /(1-\alpha-\beta)} \beta^{\beta /(1-\alpha-\beta)} \gamma^{1 /(1-\alpha-\beta)} D^{(\alpha+\beta) /(1-\alpha-\beta)} .
\end{aligned}
$$

Proposition 2. If the goal of the manufacturer and the supplier is to maximize the total profit of collaborative R\&D, they should only develop high-grade product and set its price, $P_{h}^{*}$, to be half of its value, $V_{h}^{*}$. And the product realization rate will be $\delta_{h}^{*}=$ $1 / 2$.

Proof. From (6), we can see that the R\&D investment of manufacturer and its core part supplier in mid-grade and low-grade product is 0 ; that is, they do not develop midgrade and low-grade products, only developing high-grade product.

From (4) and (5), we can obtain the following.

$$
\begin{aligned}
& V_{h}^{*}=\gamma\left(I_{e h}^{*}\right)^{\alpha}\left(I_{\text {sh }}^{*}\right)^{\beta} \\
& =2^{(1+(-1-\alpha-\beta) /(1-\alpha-\beta))} \alpha^{\alpha /(1-\alpha-\beta)} \beta^{\beta /(1-\alpha-\beta)} \gamma^{1 /(1-\alpha-\beta)} D^{(\alpha+\beta) /(1-\alpha-\beta)}
\end{aligned}
$$

Comparing (8) with (7), we can obtain $P_{h}^{*}=V_{h}^{*} / 2$. As the manufacturer and its supplier only develop high-grade product, customers of $\rho \in\left[P_{h}^{*} / V_{h}^{*}, 1\right]$ will choose to buy highgrade product; the product realization rate of high-grade product is $\delta_{h}^{*}=1-P_{h}^{*} / V_{h}^{*}=1 / 2$.

Proposition 2 shows that if the goal of the manufacturer and its supplier developing new product is to maximize the collaborative R\&D profit, they should only develop high-grade product for the high-end customers, rather than developing all the 3 grades of the product to meet the heterogeneous demands of all layers. Of course, this $R \& D$ policy will be at the expense of customer and market share. For example, as the target customers of Apple iPhone are only the high-end, in the second quarter of 2018, Apple iPhone grasped $62 \%$ of global mobile phone profit with only $11 \%$ of global mobile phone market.

Proposition 3. The manufacturer and its core part supplier should increase their investment in collaborative R\&D at the ratio of $\alpha$ : $\beta$ with the increase of the potential demand of whole series of product, $D$, or the technical level of collaborative R\&D, while raising the price of high-grade product to raise their total profit.

Proof. Respectively, solving the first-order partial derivative of R\&D investment of the manufacturer and its core part supplier, $I_{e h}^{*}$ and $I_{s h}^{*}$, price of high-grade product, $P_{h}^{*}$, total profit of supply chain, $\pi^{*}$, to the potential total demand, $D$, and technical level of collaborative R\&D, $\gamma$, we can obtain $\partial I_{e h}^{*} / \partial D>0, \partial I_{s h}^{*} / \partial D>0, \partial P_{h}^{*} / \partial D>0, \partial \pi^{*} / \partial D>0$, $\partial I_{e h}^{*} / \partial \gamma>0, \partial I_{s h}^{*} / \partial \gamma>0, \partial P_{h}^{*} / \partial \gamma>0$, and $\partial \pi^{*} / \partial \gamma>0$. Therefore, $I_{e h}^{*}, I_{s h}^{*}, P_{h}^{*}$, and $\pi^{*}$ are the monotonically increasing function of $D$ and $\gamma$. In other words, the manufacturer and its core part supplier should increase their investment in collaborative R\&D, $I_{e h}^{*}$ and $I_{s h}^{*}$, and the price of product, $P_{h}^{*}$, with the increase of $D$ and $\gamma$. And consequently, their total collaborative R\&D profit, $\pi^{*}$, increases very well.

In addition, from (4) and (5), we can obtain that $I_{e h}^{*} / I_{\text {sh }}^{*}=$ $\alpha / \beta$. Therefore, the manufacturer and its core part supplier should increase their investment in collaborative R\&D at the ratio of $\alpha: \beta$.

From Proposition 3, we know that with the increase of the potential demand of whole series of product, $D$, the improvement of the intrinsic value of product will attract more potential customers and turn more potential demands into actual demand. As a result, the total collaborative R\&D profit increases. Therefore, the manufacturer and its core part supplier should increase their investment in collaborative R\&D to improve the intrinsic value of product and, consequently, obtain more profit. Similarly, with the increase of the technical level of collaborative R\&D, the manufacturer and the supplier raising R\&D investment can better improve product's intrinsic value and, consequently, obtain more actual demands and total profit. Therefore, the manufacturer and its core part supplier should increase their investment in collaborative R\&D and the price of high-grade product to raise their total profit with the increase of the potential demand of whole series of product or the technical level of collaborative $\mathrm{R} \& \mathrm{D}$.

\subsection{The Optimal Policies Maximizing Profit with Constraint} of Sales Volume. Nowadays, as the competition becomes more and more intense, in order to better obtain a longterm and sustainable development, the manufacturer and its core part supplier have to try their best to meet demands from more layers of customers, in order to enlarge the sales volume or market share of the manufacturer's product while maximizing the total profit. In other words, their goal is not only maximizing its profit, but also taking into account the sales volume of the manufacturer's products and satisfaction 
of demands from customers of different layers. Under this condition, the manufacturer and its core part supplier face the following programming.

$$
\begin{aligned}
\max _{P_{i}, I_{e i}, I_{s i}} & \sum_{i=h, m, l}\left(P_{i} \delta_{i} D-I_{e i}-I_{s i}\right), \\
\text { s.t. } & \sum_{i=h, m, l} \delta_{i}>\bar{\delta}>0, \\
& P_{i}<V_{i}, \quad i=h, m, l, \\
& \frac{P_{i}}{P_{j}}>\frac{V_{i}}{V_{j}}, \quad i=h, m, \quad j=m, l, i \neq j, \\
& P_{i}-P_{j}<V_{i}-V_{j}, \quad i=h, m, \quad j=m, l, i \neq j, \\
& \left(P_{h} V_{l}-P_{l} V_{h}\right) \\
& <\left(P_{m} V_{l}-P_{l} V_{m}\right)+\left(P_{h} V_{m}-P_{m} V_{h}\right), \\
& P_{i}, I_{e i}, I_{s i} \geq 0, \quad i=h, m, l .
\end{aligned}
$$

$\bar{\delta}$ in (10) is the lower limit of demand realization rate for its whole series of products in order to improve the sales volume of its products. Equation (10) derives from $\sum_{i=h, m, l} \delta_{i} D>\bar{\delta} D>0$. Equations (11)-(14) are the constraints of demand realization rate of the high-, mid-, and lowgrade product being positive, respectively. Solving the above programming, we can obtain the optimal R\&D investment of the manufacturer and its core part supplier, $I_{e i}^{* *}$ and $I_{s i}^{* *}$, and the optimal price of each grade, $P_{i}^{* *}, i=h, m, l$.

\section{Profit Allocation Policy}

After the manufacturer and its core part supplier jointly develop the products and obtain the profit, $\pi^{*}$, which they should allocate appropriately. In this paper, they allocate the profit, $\pi^{*}$, through bargain. In this section, we analyze the profit allocation policy referring to the models of Roth [23] and Muthoo [24].

Referring to Roth [23], the bargaining solution of the manufacturer and its core part supplier is obtained by solving the following optimization problem.

$$
\begin{array}{ll}
\max & \left(\pi_{e}-d_{e}\right)^{\varphi}\left(\pi_{s}-d_{s}\right)^{\mu}, \\
\text { s.t. } & \left(\pi_{e}, \pi_{s}\right) \geq\left(d_{e}, d_{s}\right), \\
& \pi_{e}+\pi_{s} \leq \pi^{*}
\end{array}
$$

where $\pi_{e}$ and $\pi_{s}$ are, respectively, the profit obtained by the manufacturer and the supplier if they reach an agreement in bargaining, and $d_{e}$ and $d_{s}$ are, respectively, the profit obtained by the manufacturer and the supplier if they fail to reach an agreement. Referring to the common practice [25], we let $d_{e}=d_{s}=0 . \varphi$ and $\mu$ loosely represent the respective bargaining power of the manufacturer and the supplier, satisfying $\varphi+\mu=1$.

In reality, the manufacturer and the supplier have their own expected profit for the bargaining, $\bar{\pi}_{e}$ and $\bar{\pi}_{s}$. Before bargaining, they make commitments of accepting no less than their expected profit, $\bar{\pi}_{e}$ and $\bar{\pi}_{s}$. However, their commitments are partial or revocable; in other words, they may accept an allocation of profit lower than their expected ones. As a matter of course, the revoke of commitment will be at a certain cost, $c_{i}, i=e, s$. The revoke cost is mainly that the manufacturer or the supplier loses its credibility in its future collaboration. If the allocation of profit obtained by the manufacturer or the supplier is no less than its expectation, it does not revoke its commitment. Therefore, $c_{i}=0$ if $\bar{\pi}_{i} \leq \pi_{i}, i=e, s$. If the allocation of profit obtained by the manufacturer or the supplier is less than its expectation, the manufacturer or the supplier will bear the revoke cost, $c_{i}=$ $\tau_{i}\left(\bar{\pi}_{i}-\pi_{i}\right)$, where $\tau_{i}>0$. The function of revoke cost shows that the bigger the difference between profits of allocation and expectation is, the bigger the revoke cost is. Similarly, the bigger $\tau_{i}$ is, the bigger the revoke cost is.

Now, we can get the revoke cost as follows.

$$
c_{i}=\left\{\begin{array}{ll}
0 & \bar{\pi}_{i} \leq \pi_{i} \\
\tau_{i}\left(\bar{\pi}_{i}-\pi_{i}\right) & \bar{\pi}_{i}>\pi_{i}
\end{array}, \quad i=e, s .\right.
$$

Muthoo [24] proved that the unique Nash equilibrium of the bargaining is

$$
\begin{aligned}
\left(\pi_{e}^{*}, \pi_{s}^{*}\right) & =\left(\bar{\pi}_{e}^{*}, \bar{\pi}_{s}^{*}\right)=\left(\varphi \pi^{*}, \mu \pi^{*}\right) \\
& =\left(\frac{1+\tau_{e}}{2+\tau_{e}+\tau_{s}} \pi^{*}, \frac{1+\tau_{s}}{2+\tau_{e}+\tau_{s}} \pi^{*}\right) .
\end{aligned}
$$

From (18), we can obtain the relationships between $\varphi, \mu$ and $\tau_{e}, \tau_{s}$ as

$$
\begin{gathered}
\varphi=\frac{1+\tau_{e}}{2+\tau_{e}+\tau_{s}}, \\
\mu=\frac{1+\tau_{s}}{2+\tau_{e}+\tau_{s}} .
\end{gathered}
$$

Proposition 4. The manufacturer and the supplier should try to raise their revoke cost to strengthen their bargaining power and consequently obtain more profit in allocation.

Proof. From (19), we can find that the bigger $\tau_{e}$ or $\tau_{s}$ is, the bigger $\varphi$ or $\mu$ is. In other words, the increase of $\tau_{e}$ results in the increase of the manufacturer's revoke cost or the enhancement of the credibility of the manufacturer's commitment. Therefore, the bargaining power of the manufacturer is strengthened with the increase of $\tau_{e}$. And it is the same for the relationship between the bargaining power of the supplier, $\mu$, and $\tau_{s}$.

From (18), we can find that the bigger the bargaining power of the manufacturer, $\varphi$, is, the more the profit allocated to the manufacturer is. And it is the same for the supplier.

Therefore, the manufacturer and the supplier should try to raise their revoke cost to strengthen their bargaining power and consequently obtain more profit in allocation.

From Proposition 4, we can find that the bigger the revoke cost of the manufacturer or the supplier is, the bigger its 
allocated profit is. That is because when the revoke cost of the manufacturer or the supplier is bigger, it makes its commitment on its requiring profit more carefully, and its commitment on its profit is more reliable. Therefore, the bargaining power of the manufacturer or the supplier is stronger, and it can claim and obtain more profit in the bargain.

In reality, $\tau_{i}, i=e, s$, is affected by many factors, such as firms' reputation and scale, especially, the investment in the collaborative R\&D. The better a firm's reputation is, the bigger its revoke cost and bargaining power are. Similarly, the more investment a firm makes, the bigger its revoke cost and bargaining power are and, as a result, the more profit it can obtain in the bargain.

\section{Experimental Analysis}

A manufacturer and its core part supplier jointly develop a series of products with potential total demand, $D=50000$. The technical levels of R\&D cooperation of two parties are $\gamma=$ 0.001 and $\lambda=0.1$, respectively. Their R\&D investment output elastic coefficients are $\alpha=0.6$ and $\beta=0.3$, respectively. And their revoke cost coefficients are $\tau_{e}=6$ and $\tau_{s}=2$, respectively.

If the supply chain aims to maximize the total profit of cooperative R\&D, through (4)-(7), we can obtain the optimal $\mathrm{R} \& \mathrm{D}$ investments of the manufacturer and its core part supplier as $I_{e h}^{*}=7.0392 \times 10^{7}, I_{s h}^{*}=3.5196 \times 10^{7}$, and $I_{e m}^{*}=I_{e l}^{*}=I_{s m}^{*}=I_{s l}^{*}=0$; in other words, the supply chain only develops high-grade product with the intrinsic value of $V_{h}^{*}=9385.60$, whose optimal price and demand realization rate are $P_{h}^{*}=4692.80$ and $\delta_{h}^{*}=0.5$, respectively. And the maximal total profit of the supply chain is $\pi^{*}=1.1732 \times 10^{7}$. Finally, the manufacturer obtains profit $\varphi \pi^{*}=0.8212 \times 10^{7}$, and the supplier obtains profit $\mu \pi^{*}=0.3520 \times 10^{7}$.

If the manufacturer expect the profit maximization, at the same time, taking into account the market share and requiring a lower limit of demand realization rate of entire series of products to be $\bar{\delta}=55 \%$, we can use Matlab software to solve (8)-(14) and obtain the optimal R\&D investments of the manufacturer and its core component supplier as $I_{e h}^{* *}=$ $7.0650 \times 10^{7}, I_{s h}^{* *}=3.5325 \times 10^{7}$, and $I_{e m}^{* *}=7.8256 \times 10^{4}$; $I_{s m}^{* *}=3.9128 \times 10^{4}, I_{e l}^{* *}=1.2628 \times 10^{5}$, and $I_{s l}^{* *}=0.6314 \times 10^{5}$, respectively. And the intrinsic value of each grade is $V_{h}^{* *}=$ 9416.45, $V_{m}^{* *}=7356.52$, and $V_{l}^{* *}=4187.87$. Their optimal prices are $P_{h}^{* *}=4505.25, P_{m}^{* *}=3472.73$, and $P_{l}^{* *}=1884.54$, and demand realization rates are $\delta_{h}^{* *}=0.4988, \delta_{m}^{* *}=$ 0.00002 , and $\delta_{l}^{* *}=0.0512$, respectively. The total demand realization rate is $\delta^{* *}=0.55002$, and the total profit of the supply chain is $\pi^{* *}=1.0940 \times 10^{7}$. Finally, the manufacturer obtains profit $\varphi \pi^{* *}=0.7658 \times 10^{7}$, and the supplier obtains profit $\mu \pi^{* *}=0.3282 \times 10^{7}$.

Comparing the above two optimal solutions, we can find that the manufacturer increases the total sales volume, or total demand realization rate, at the expense of profit. We also found that the source of increasing in total demand realization rate is mainly low-grade product, while the demand of mid-grade product is very small, and the demand of highgrade product declines slightly. Therefore, the manufacturer who develops high-grade product to maximize its profit should double think when it decides to seek more market share with mid-and low-grade product. As it not only reduces its profits, but also may damage the image of its high-grade product, reducing the demand of its high-grade product. In addition, the manufacturer can just develop high-grade and low-grade products without mid-grade product, as the demand of the mid-grade product is very small.

\section{Case Study}

In this section, we use the case of Apple's product development policy to mainly illustrate Proposition 1 and the two conclusions of experimental analysis. The first is that, at the expense of profit, the total sales volume of the product family, or the total demand realization rate, can be increased, whose main source is low-grade product. And the second is that mid-grade product makes little contribution to the total sales volume.

In 2004, Apple convened more than 1000 internal staff members, including the iPhone designer Jonathan Ive and established the iPhone team to carry out the project classified as highly confidential, named "Project Purple". The CEO of Apple at that time, Steve Jobs, changed the original focus of Apple, such as tablet pc, iPad, into cell phone.

On June 29, 2007, the first generation of iPhone was officially launched in the United States; the two models were priced at US \$ 499 for 4GB model and US \$ 599 for 8GB model in the United States. There were hundreds of Apple fans kept in line outside Apple's sales shop to purchase iPhone. The launch of the iPhone immediately caused a panic buying boom.

On September 12, 2012, Apple introduced its sixthgeneration iPhone products, iPhone 5, which also was crazily sought after by customers. The first 6 th-generation products of Apple's iPhone have always adhered to its high-grade route, only developing high-grade products. This high-grade route policy earned high profits for Apple. According to IDC data, in 2012, the profits of iPhone accounted for $75 \%$ of the global smart phone market profits, while its shipments just accounted for $19.1 \%$ of the global smart phone market share.

The above 3 paragraphs show that when Apple Company insisted on its high-end positioning, only developing and selling high-grade products, its profit was maximized. It illustrates Proposition 1 in this paper.

However, from 2013, market share and sales of Samsung smart phones in the global smart phone market comprehensively surpassed Apple. In the first quarter of 2013, the shipments of Samsung smartphone was 70.7 million, accounting for $32.7 \%$ of the whole global market, and sales were 23.621 billion US dollars, while Apple sold 37.4 million iPhones with global market share of $17.3 \%$, and its sales were 22.955 billion US dollars. Although Apple's profit share was $57 \%$, higher than Samsung's profit share of $43 \%$ (Nokia, BlackBerry, Motorola, and other manufacturers profits were negative), the gap between the two company was getting smaller and smaller. In the second quarter of 2013, the gap further shrank to Apple 53\% and Samsung 50\%. Apple had to change its policy of single model to conquer the world. 
On September 10, 2013, in the high-profile press conference held in Cupertino, California, United States, Apple revealed the introduction of two new iPhone models: iPhone 5C and iPhone 5S. Among them, iPhone 5C grade was slightly lower than the previous generation of iPhone 5. However, due to the high price of iPhone $5 \mathrm{C}$, its sales were lower than Apple's expectation, and there was product backlog of iPhone 5C. At the same time, in order to occupy further lower level of the market, in December 2013, Apple restored the production and sales of iPhone 4 in India, Indonesia, Brazil, and other lower level markets. Under this new product development policy, in the fourth quarter of 2013, Apple sold 51 million iPhones with an increasing rate of $6.7 \%$, compared to 47.8 million in the same quarter of 2012 . However, the net profit in the fourth quarter of 2013 is $\$ 13.1$ billion with almost no change, compared to $\$ 13.1$ billion in the year-ago quarter.

From the above paragraph, we can find that iPhone 5C, a mid-grade product, make little contribution to the total sales volume of iPhone series, while iPhone 4 , a low-grade product in the end of 2013, made a big contribution to the total sales volume of iPhone series. It illustrates the two conclusions of experimental analysis. The above paragraph also shows that even Apple, whose position is high-end product, had to provide low-grade product to the market to enlarge sales volume and market share when facing fierce competition.

\section{Conclusions}

In this paper, we proposed a collaborative R\&D model of a manufacturer and its core part supplier jointly developing three grades of products of the same series, in order to study their collaborative R\&D decision and product pricing policy. And we established a bargaining game model to research how they allocate the $R \& D$ profit. We found that if the supply chain aims to maximize profits, it should only develop high-grade product and set its price to half of its intrinsic value. If the supply chain plans to obtain larger sales volume or market share of its series of products while maximizing its profit, it should at least develop high- and low-grade products to cover more layers of customers, while making its product price of each grade lower than its intrinsic value and making the price ratio of higher grade product to lower grade product greater than their intrinsic value ratio, and their price gap should be less than the gap of their intrinsic value. In the bargain of allocating profit, the manufacturer and the supplier should try to raise their revoke cost to strengthen their bargaining power and, consequently, obtain more profit in allocation.

\section{Data Availability}

All the data used to support the findings of this study are included within the article.

\section{Conflicts of Interest}

The authors declare no conflicts of interest.

\section{Authors' Contributions}

Bo Huang had the original idea for the study and developed the model. Bo Huang and Yuyu Li made model analysis, experimental analysis, and case study. Thomas L. Saaty made suggestions on improving the model and the model analysis. Yuyu Li and Bo Huang drafted the manuscript, which was revised by all authors.

\section{Acknowledgments}

This research is supported by the National Natural Science Foundation of China (No. 71573025), National Social Science Foundation of China (No. 17XGL008), and the Fundamental Research Funds for the Central Universities (No. 2018CDXYJG0040). This paper is dedicated to Thomas L. Saaty, who was a respected supervisor.

\section{References}

[1] Y.-J. Chen, B. Tomlin, and Y. Wang, "Coproduct technologies: Product line design and process innovation," Management Science, vol. 59, no. 12, pp. 2772-2789, 2013.

[2] Y. Rong, Y.-J. Chen, and Z. M. Shen, "The impact of demand uncertainty on product line design under endogenous substitution," Naval Research Logistics (NRL), vol. 62, no. 2, pp. 143-157, 2015.

[3] Unknown, "Customer-oriented product innovation is the best innovation," China Paper Newsletter, vol. 27, no. 5, pp. 25-26, 2012.

[4] S. Cannella, M. López-Campos, R. Dominguez, J. Ashayeri, and P. A. Miranda, "A simulation model of a coordinated decentralized supply chain," International Transactions in Operational Research, vol. 22, no. 4, pp. 735-756, 2015.

[5] S. Karray and S. P. Sigué, "A game-theoretic model for copromotions: Choosing a complementary versus an independent product ally," OMEGA - The International Journal of Management Science, vol. 54, pp. 84-100, 2015.

[6] V. K. Kaishev, J. P. Nielsen, and F. Thuring, "Optimal customer selection for cross-selling of financial services products," Expert Systems with Applications, vol. 40, no. 5, pp. 1748-1757, 2013.

[7] N. Bhatnagar, K. Maryott, and D. Bejou, "Customer selection and prioritization: The optimal resource allocation approach to maximizing customer value," Journal of Relationship Marketing, vol. 6, no. 3-4, pp. 117-130, 2007.

[8] S. Laari, J. Töyli, T. Solakivi, and L. Ojala, "Firm performance and customer-driven green supply chain management," Journal of Cleaner Production, vol. 112, pp. 1960-1970, 2016.

[9] Y. Y. Li and B. Huang, "Product Selection and Components Replenishment Model of ATO Manufacturer under Heterogeneous Demand," Journal of Applied Mathematics, vol. 2013, Article ID 714715, 8 pages, 2013.

[10] X.-F. Shao and J.-H. Ji, "Effects of sourcing structure on performance in a multiple-product assemble-to-order supply chain," European Journal of Operational Research, vol. 192, no. 3, pp. 981-1000, 2009.

[11] C. Schön, "On the product line selection problem under attraction choice models of consumer behavior," European Journal of Operational Research, vol. 206, no. 1, pp. 260-264, 2010. 
[12] C. Schön, "On the Optimal Product Line Selection Problem with Price Discrimination," Management Science, vol. 56, no. 5, pp. 896-902, 2010.

[13] Y. Y. Li, B. Dan, and B. Huang, "Pricing and replenishment policy of product family ATO manufacturer based on customerdriven demand substitution," Systems Engineering, vol. 26, no. 6, pp. 817-824, 2012.

[14] X. F. Ding, B. Dan, W. J. He, and H. H. Zheng, "The optimal pricing policy for remanufactured products considering luxury and green preferences in the market," Chinese Journal of Management Science, vol. 21, no. 5, pp. 94-102, 2013.

[15] Z. Ge, Q. Hu, and Y. Xia, "Firms' R\&D cooperation behavior in a supply chain," Production Engineering Research and Development, vol. 23, no. 4, pp. 599-609, 2014.

[16] M. R. Frascatore, "R\&D cost sharing along the supply chain," Journal of Business \& Economics, vol. 10, pp. 1-11, 2011.

[17] K. Matsui, "Cost-based transfer pricing under R\&D risk aversion in an integrated supply chain," International Journal of Production Economics, vol. 139, no. 1, pp. 69-79, 2012.

[18] R. Wang, J. H. Ji, and X. G. Ming, "R\&D partnership contract coordination of information goods supply chain in government subsidy," International Journal of Computer Applications in Technology, vol. 37, no. 3, pp. 297-306, 2010.

[19] W. Cheng, X. M. Zhang, and H. Song, "A study on the relational contract of knowledge trading among members in the supply chain based on the perspective of cooperative innovation," Science Research Management, vol. 36, no. 7, pp. 38-48, 2015.

[20] W. Xu, S. Q. Zheng, and D. P. Chen, "Study on collaboration and innovation model of manufactures sellers in the closedloop supply chain," Chinese Journal of Management Science, vol. 22, no. 7, pp. 116-123, 2014.

[21] A. Breiter, T. Hegmanns, B. Hellingrath, and S. Spinler, "Coordination in supply chain management-review and identification of directions for future research," Logistik Management, pp. 135, 2009.

[22] L. Xu, D. Liang, Z. Duan, and X. Xiao, "Stability analysis of RD cooperation in a supply chain," Mathematical Problems in Engineering, vol. 2015, Article ID 409286, 10 pages, 2015.

[23] A. Roth, Axiomatic Models in Bargaining, Springer-Verlag, Germany, 1979.

[24] A. Muthoo, "A bargaining model based on the commitment tactic," Journal of Economic Theory, vol. 69, no. 1, pp. 134-152, 1996.

[25] Y. Li, B. Huang, and F. Tao, "Pricing mechanism design for centralized pollutant treatment with SME alliances," International Journal of Environmental Research and Public Health, vol. 13, no. 6, pp. 1-13, 2016. 


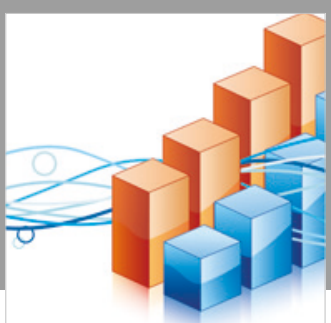

Advances in

Operations Research

\section{-n-m}
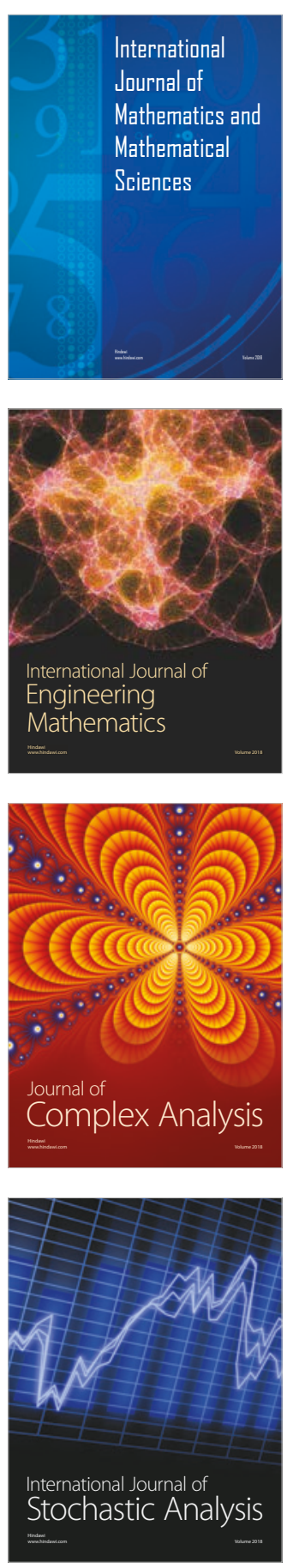
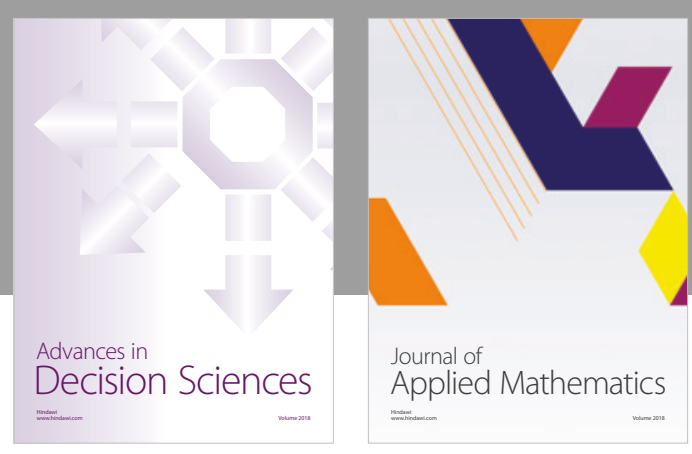

Journal of

Applied Mathematics
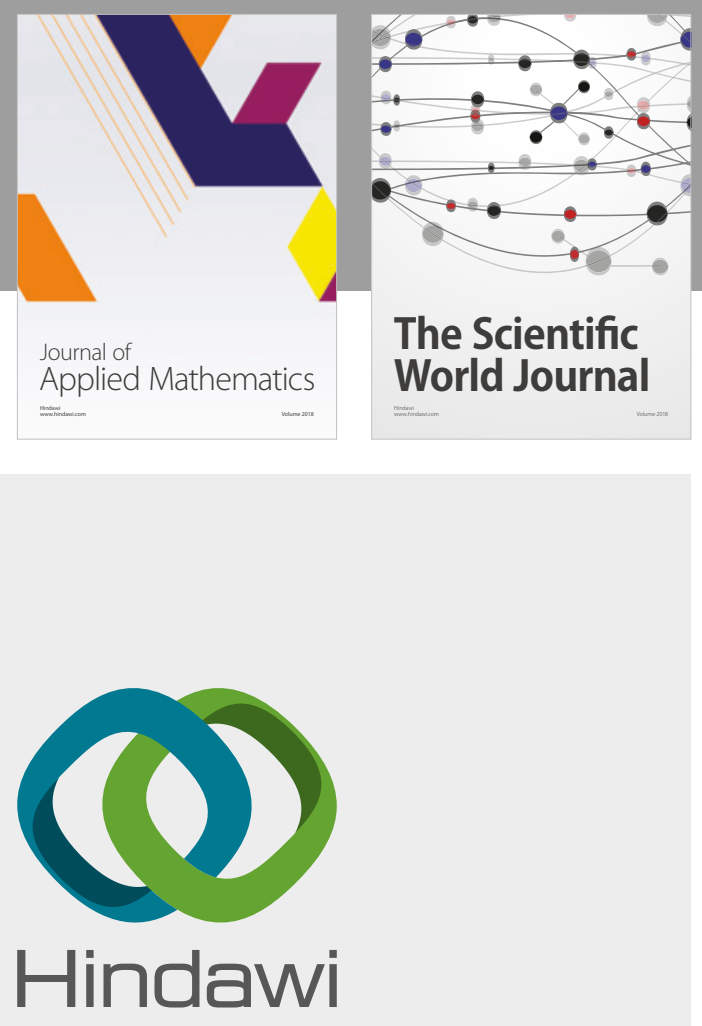

Submit your manuscripts at

www.hindawi.com

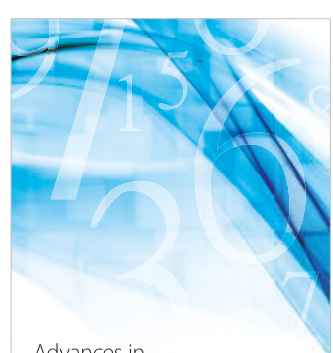

Advances in
Numerical Analysis
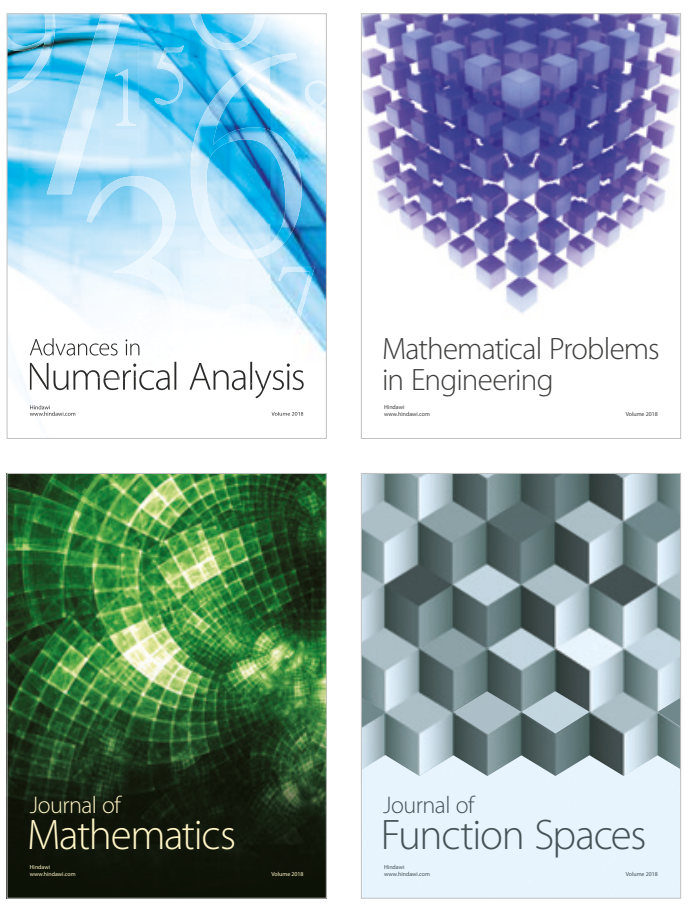

Mathematical Problems in Engineering

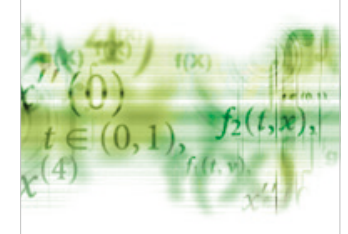

International Journal of

Differential Equations

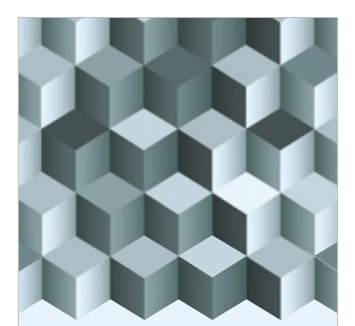

Journal of

Function Spaces

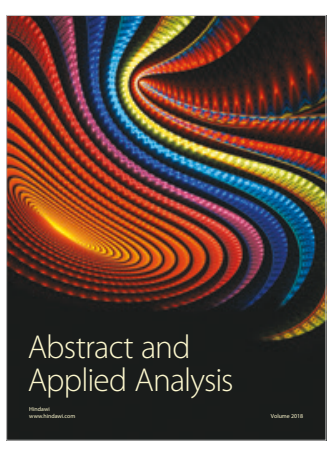

The Scientific

World Journal

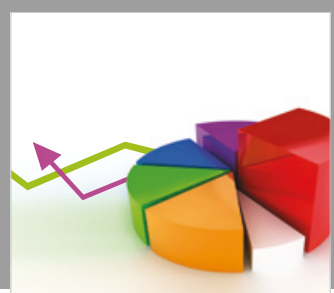

Journal of

Probability and Statistics
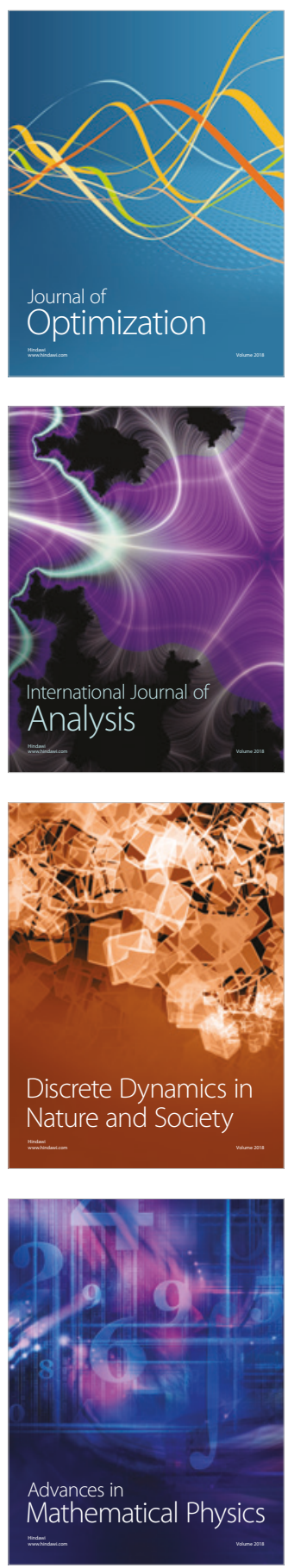